\title{
Nucleotide Sequencing of Bovine $\alpha 4$ Integrin cDNA, and its Expression in the Primarily-cultured Skeletal Muscle Satellite Cells
}

\author{
Susumu MUROYA, Ikuyo NAKAJIMA and Koichi CHIKUNI \\ National Institute of Livestock and Grassland Science, Tsukuba Norin Kenkyu Danchi, \\ Ibaraki-ken 305-0901, Japan
}

(Received May 8, 2001 ; Accepted August 1, 2001)

\begin{abstract}
Alpha 4 integrin has been known to play an important role in the myotube formation of mouse skeletal muscle satellite cells on the myotube surface. In the present study, the 3480-bp nucleotide sequence of the bovine $\alpha 4$ integrin cDNA was determined, including the entire coding region of 1033 amino acids. The bovine $\alpha 4$ integrin cDNA has $81.4 \%$ and $87.2 \%$ identity with the mouse and human $\alpha 4$ integrin nucleotide sequences, respectively. The deduced amino acid sequence of the bovine $\alpha 4$ integrin mature protein showed $81.1 \%$ and $85.9 \%$ identity with the mouse and human $\alpha 4$ integrin amino acid sequence, respectively. An RT-PCR analysis showed that bovine $\alpha 4$ integrin was expressed in both the proliferating and differentiating primarily-cultured skeletal muscle satellite cells at higher levels than in the muscle tissue. This expression before the differentiation suggests that $\alpha 4$ integrin plays a role in proliferating mononucleated satellite cells in skeletal myogenesis.
\end{abstract}

Animal Science Journal 72 (6) : 505-512, 2001

Key words : $\alpha 4$ Integrin, Bovine, Myotube formation, Skeletal muscle satellite cell

Alpha 4 integrin has been found as a subunit of very late antigen-4 (VLA-4), and can interact with vascular cell adhesion molecule-1 (VCAM-1) and fibronectin by pairing with its counterpart, $\beta 1$ integrin ${ }^{7}$. The interaction between the $\alpha 4$ integrin on the surface of leukocytes and the VCAM-1 on the surface of endothelial cells is crucial for the recruitment of leukocytes to the endothelium ${ }^{2)}$. Alpha 4 integrin can also pair with the $\beta 7$ integrin and the $\alpha 4 \beta 7$ heterodimer on the surface of leukocytes, and can bind to VCAM-1 and mucosal addressin cell adhesion molecule-1 (MAdCAM-1) ${ }^{7}$. Besides the immune system, the hematopoiesis and neural crest migration system of various vertebrates employ the interaction of the $\alpha 4$ integrin with VCAM-1 and fibronectin. The $\alpha 4$ integrin is expressed in a subset of the neural crest cells, somites, neural tissues, and gut endoderm in chicken embryos ${ }^{19)}$. Mouse embryos also display a widespread pattern of the expression, including tissues such as blood islands, developing blood vessels, the neural crest, the dorsal root ganglia, and smooth and skeletal muscle ${ }^{17}$. The xenopus protein is observed in the epidermis and gills of tadpole stage embryos after the tailbud stages of development ${ }^{23)}$. Furthermore, mice lacking the $\alpha 4$ integrin die embryolonically due to defective chorion-allantois fusion and cardiac hemorrhage ${ }^{24)}$.

Alpha 4 integrin has also been known to play a role in myotube formation. In mammalian skeletal muscle differentiation ${ }^{13,16,20)}$, an early-born population of myoblasts (primary myoblasts) fuse to form primary myotubes, after which a distinct population of myoblasts (secondary myoblasts) align along the primary myotubes. The primary myotubes apparently function as a template for secondary myotube formation by secondary myoblasts. Most adult skeletal muscle fibers are composed of secondary myotubes. Alpha 4 integrin is present on primary myotubes with

Corresponding : Susumu MUROYA (fax : +81 (0) 298-38-8683, e-mail : muros@affrc.go.jp)

Anim. Sci. J. 72 (6) : 505-512, 2001 


\section{MUROYA, NAKAJIMA and CHIKUNI}

$\beta 1$ integrin, and VCAM-1 is present on secondary myoblasts and portions of secondary myotubes that are apposed to primary myotubes ${ }^{8,15,17)}$. Antibodies raised against the $\alpha 4$ integrin and VCAM- 1 inhibited myotube formation of the mouse satellite cell line, $\mathrm{C} 2 \mathrm{C} 12^{15)}$.

This data suggests that $\alpha 4$ integrin and VCAM-1 play a role in the alignment of secondary myoblasts along primary myotubes, and/or the subsequent fusion of the secondary myoblasts into secondary myotubes. Furthermore, in adult skeletal muscle, VCAM-1 expression persists on the satellite cells ${ }^{8,15}$, which are wedged between the basal lamina and the muscle fibers. This finding suggests that the $\alpha 4 \beta 1$ integrin and VCAM-1 may also play a role in muscle repair $^{2,6)}$.

Thus, the $\alpha 4$ integrin plays important roles in various developmental aspects in vertebrates. It probably also plays a crucial role in the skeletal muscle development of domestic animals. Alpha 4 integrin is expected to change muscle fiber size if the molecule is functionally modified. Studies targeting $\alpha 4$ integrin may contribute to both qualitative and quantitative improvement of meat production. In this study, the role of the $\alpha 4$ integrin in bovine muscle development was studied. To investigate the expression of the $\alpha 4$ integrin during the development of skeletal muscle cells by RT-PCR, use of the specific primers for the bovine cDNA nucleotide sequence is a requisite. At the end of this study, the nucleotide sequence of the bovine $\alpha 4$ integrin cDNA was determined. Then expression of the $\alpha 4$ integrin in bovine muscle tissue and the primarily-cultured satellite cells was analyzed by RT-PCR using the bovine specific primers.

\section{Materials and Methods}

\section{Cell preparation and culture}

To prepare bovine muscle satellite cells, a biceps femoris muscle was excised within $3 \mathrm{~min}$ after slaughter from a six-month-aged Holstein cow bred in the National Institute of Livestock and Grassland Sceince. The cell preparation described below was performed according to the method originally designed by Nara et $a l^{11}{ }^{11}$. The muscle was finely minced and was then digested in Dulbecco's modified Eagle medium (DMEM) (Gibco, Grand Island, NY, USA) containing $0.1 \%$ collagenase (Sigma Chem., St. Louis, MO, USA), $0.1 \%$ hyaluronidase (Wako Pure Chem., Osaka, Japan), and 1,000 U/ml dispase (Godo Shusei, Tokyo, Japan) at $37^{\circ} \mathrm{C}$ for $20 \mathrm{~min}$. Digested tissue was filtered in a $70 \mu \mathrm{m}$ mesh filter. After un. dergoing centrifugal purification twice, the obtained cells were cultured as primary skeletal muscle satellite cells in a DMEM containing $10 \%$ fetal calf serum (FCS) (Biological Industries, Kibbutz Beit Haemek, Israel), $100 \mathrm{IU} / \mathrm{m} l$ penicillin (Sanko Pure Chem., Tokyo, Japan), and $100 \mathrm{mg} / \mathrm{m} /$ streptomycin (Sanko Pure Chem.). The cells were then maintained in a humidified atmosphere of $5 \% \mathrm{CO}_{2}$ at $37^{\circ} \mathrm{C}$, and the medium was renewed every three days. More than $90 \%$ of the skeletal muscle cells used in this study were stained by an anti-chicken desmin monoclonal antibody (data not shown) (Chemicon, Temecula, CA, USA), which specifically reacts with bovine desmin in cultured muscle cells. To encourage myotube formation, the cells were induced to differentiate by serum-free COSMEDIUM (Cosmobio, Tokyo, Japan) when they reached confluence.

mRNA preparation and nucleotide sequence determination

Using ISOGEN (NipponGene, Tokyo, Japan), total RNA was extracted from the bovine biceps femoris and the satellite cells at several culture points from the growth stage to the myotube formation stage.

The first-strand cDNA was synthesized from $0.5 \mu \mathrm{g}$ of total RNA using M-MLV Reverse Transcriptase RNase-H minus (Toyobo, Tokyo, Japan) with the primer 3ADP1. The sequences of all the primers used in this study are shown in Table 1. The muscle cells at differentiation induction were used as the mRNA source for nucleotide sequence determination of the $\alpha 4$ integrin cDNA.

Initially, primers designed for the human $\alpha 4$ integrin cDNA sequence ${ }^{21)}$ were used. Using the obtained cDNA as a template, three fragments using three primer sets, VLA11-VLAR5, VLA13-VLAR7, VLA8-VLAR1, VLA3-VLAR4, and VLA6-VLAR4 with AmpliTaq Gold (Perkin-Elmer, Foster City, CA, 
Table 1. PCR primers used in this study

\begin{tabular}{|c|c|}
\hline VLA3 & 5'-GGAAAATGGAAAGTGGAAAAGAAGCCAG-3' \\
\hline VLA6 & 5'-TTTAGAGCTGGAAGAGAAGCAAATAAACTG-3' \\
\hline VLA7 & $5^{\prime}$-CCTGTAGTAATTGTTGACGCTTCTTTAAGC-3' \\
\hline VLA8 & 5'-TCATTTTCGGAGCCAGCATACTACCGA-3' \\
\hline VLAll & 5'-CCAACCGTCGCATCCCGTGCAACT-3' \\
\hline VLA13 & $5^{\prime}$-TGATCAATCCCGGGGCGATTTACAGATG-3' \\
\hline VLA14 & 5'ATGTTCCCCACCGAGAGCGCATGGCT-3' \\
\hline VLAR1 & 5'-GAGAAATAGAATCTTGGTGGAGACTCTGC-3' \\
\hline VLAR4 & 5'AGATTTGTATTGTCTTTTAAAGAAGCCAGC-3' \\
\hline VLAR5 & 5'-CGGGATTCTTTCCGATCCTGCATCTGTA-3' \\
\hline VLAR7 & 5'AAAACTGGATATTCCAGCTTGACATGATGC-3' \\
\hline VLAR8 & 5'AACACGGAGCTATTCTTTTACTCAGTTCTG-3' \\
\hline VLAR9 & 5'-ATCTGAGAAGCCATCTGCATTGAGGTC-3' \\
\hline intg1 & 5'AGTTGGAAGGTCGGCCATCCATTTTAG-3' \\
\hline intg 3 & 5'ATGCCTTCTGATTTACGAACAGAACTGAGT-3' \\
\hline intgR4 & 5'-GCTTTCTTCTGGATGCCAGCTCACT-3' \\
\hline ALP4F & 5'-GGAAAATGGACAGTGGAAAAGAAGCCAG-3' \\
\hline ALP4R & $5^{\prime}$-AGATTGGTACTGTCTTTTGAAGAAGCCAGC-3' \\
\hline 3ADP1 & $5^{\prime} \times$ CTGCAGGAATTCGATATCGAAGCTTGC-3' \\
\hline 3ADP2 & 5'-CTGCAGGAATTCGATATCGAAGC-3' \\
\hline
\end{tabular}

USA) were amplified. After nucleotide sequence determination of these fragments, using both human and bovine specific primers, extending the sequencing both upwards and downwards from the fragments was tried. Amplifications for the next sequencing were performed using primer sets, intg3-VLAR9, VLA7 -intgR4, and intg1-3ADP2. To reconfirm the 5' end sequence encoding potential signal peptide, another primer set, VLA14-VLAR8, for the amplification and performed the nucleotide sequence determination were used.

All the bands of the amplified fragments were purified by excision from $4 \%$ agarose gel after electrophoresis. Using these fragments as templates, a second PCR and a subsequent purification were performed. These purified products were used as templates for direct sequencing with the ABI PRISM Dye Terminator Cycle Sequencing Ready Reaction Kit (Perkin-Elmer), and the 373A DNA sequencer.

\section{Expression analysis by $R T-P C R$}

In this experiment, $\alpha 4$ integrin expression in the muscle tissue (biceps femoris) and the muscle cells during its proliferation and myotube formation was analyzed. The primers ALP4F (forward), and ALP $4 R$ (reverse), for the expression analysis were employed. The fragment between ALP4F-ALP4R was amplified using AmpliTaq Gold. The PCR procedures using AmpliTaq Gold were carried out first for $9 \mathrm{~min}$ at $95^{\circ} \mathrm{C}$, followed by 36 cycles of $30 \mathrm{sec}$ at $95^{\circ} \mathrm{C}, 30 \mathrm{sec}$ at $55^{\circ} \mathrm{C}, 30 \mathrm{sec}$ at $72^{\circ} \mathrm{C}$, and finally $7 \mathrm{~min}$ at $72^{\circ} \mathrm{C}$ in the presence of $5 \%$ dimethylsulfoxide. In the analysis, the ribosomal protein L7 (RPL7) was adopted as a standard. The nucleotide sequences of forward and reverse PCR primers for RPL7, 5'GCAGAACCCAAATTGGCGTTTGTCATCAG-3' and 5'-GAAGACAATTTGAAGGGCCACAGGAAGT-3', respectively, were designed based on mouse RPL7 sequences that are completely conserved in human sequences. Electrophoresis was conducted using $4 \%$ agarose gel under the condition of $100 \mathrm{~V}, 30$ min.

\section{Results}

The mRNA nucleotide sequences of the bovine $\alpha 4$ integrin containing its complete 3102 -bp coding region were determined. The nucleotide sequence data reported in this paper appear in the DDBJ/EMBL/ GenBank nucleotide sequence databases with the accession number $\mathrm{AB} 055841$. The bovine $\alpha 4$ integrin cDNA had $81.4 \%$ and $87.2 \%$ identity with the mouse $^{123}$ and human ${ }^{21} \alpha 4$ integrin nucleotide sequence (accession numbers X53176 and L12002), respectively. In comparison to the mouse and human sequences, a difference was found, as the presence of two guanine bases at positions 88 and 89 in the bovine sequence were absent from the human sequence (Fig. 1a). This insertion of two bases causes a shift of the reading frame in the bovine $\alpha 4$ integrin mRNA. Therefore, it is concluded that the translation of bovine $\alpha 4$ integrin mRNA initiates from the ATG at position 51-53.

The bovine $\alpha 4$ integrin cDNA are predicted to encode the protein of 1033 amino acids (aa), which is shorter than those of mice $(1039-a a)^{12)}$ and humans $(1038-a)^{21)}$ (Fig. 1b). This two base insertion was observed in the region encoding the 33-aa signal peptide (SP) predicted by analogy to the mouse and 
MUROYA, NAKAJIMA and CHIKUNI

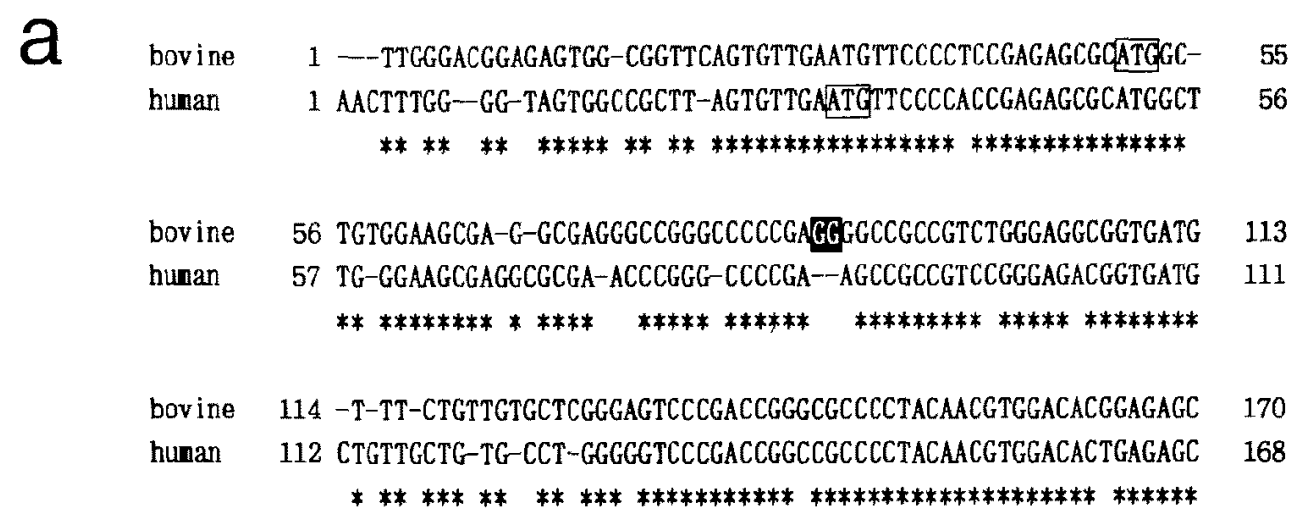

Fig. 1. (a) Nucleotide sequence of bovine and human $\alpha 4$ integrin cDNA. Initiation codon is boxed and identical bases between bovine and human are marked with asterisks. Inverted GG in bovine sequence is putative inserted bases. (b) Comparison of deduced amino acid sequences of bovine, human, and mouse $\alpha 4$ integrin. Signal peptide and transmembrane region are on dashed and wavy line, respectively. Calreticulin binding site (GFFKR) and ligand binding site (YWTG) are bolded and boxed, respectively. Putative divalent cation binding domains are inverted and a protease cleavage site is double underlined. The cysteine residues that are predicted to form disulphide bridge, and potential $\mathrm{N}$-glycosylation sites are bold underlined and shadowed, respectively. The region corresponding to CDNA fragment amplified by RT-PCR is single underlined. Asterisks and dots indicate the completely conserved residues and the identical residues between two animals, respectively. The bovine nucleotide sequence data appear in the $\mathrm{DDBJ} / \mathrm{EMBL} / \mathrm{GenBank}$ nucleotide sequence databases with the accession number $\mathrm{AB}$ 055841 .

human sequence. The mature proteins of the bovine $\alpha 4$ integrin have a 943 -aa extracellular region with a 23-aa transmembrane (TM) region and a 34-aa cytoplasmic (CP) tail. The deduced amino acid sequence of the bovine $\alpha 4$ integrin mature protein showed $81.1 \%$ and $85.9 \%$ identity with the mouse and human $\alpha 4$ integrin amino acid sequence, respectively.

Twelve potential $\mathrm{N}$-glycosylation sites were found in the extracellular region, ten positions of which were conserved in the mouse and human $\alpha 4$ integrin. Twenty-four cysteine residues that potentially form a disulfide bond ${ }^{183}$ were also completely conserved among the mouse and human $\alpha 4$ integrin. The bovine $\alpha 4$ integrin has a potential protease cleavage site (KKEK at positions 606-609), at which the human and xenopus $\alpha 4$ integrin are reported to be cleaved $^{21,23)}$. Conserved residues YWTG at positions 220-223 are critical for cell adhesion to both the VCAM-1 and CS-1 region of fibronectin ${ }^{5}$. The bovine 143-164 and 270-280 domains of the $\alpha 4$ integrin are also highly similar (90\% and $100 \%$, respectively) to those of the human protein that are essential for adhesion to the VCAM-1 and CS-1 peptide ${ }^{6)}$.

Anim. Sci. J. 72 (6) : 505-512, 2001
The pentapeptide GFFKR (residues 1003-1007) that is contained in the cytoplasmic region of all the integrin $\alpha$ subunits in common was also conserved in the bovine $\alpha 4$ integrin. This motif, known as the conserved calreticulin binding site ${ }^{14)}$, plays an important role in ligand binding ${ }^{1}$. Highly conserved (100\% of similarity) divalent cation binding sites, at positions $314-321,377-384$, and $439-447$, are reported to contain important residues for ligand binding ${ }^{9}$.

To examine the expression pattern of the $\alpha 4$ integrin in bovine muscle tissue and the satellite cell culture, multiplex PCR was carried out with an internal standard RPL7 using the bovine specific primer set ALP4F -ALP4R. The primer set was designed to amplify the 314-bp fragment of the bovine $\alpha 4$ integrin (Fig. 1b). Before differentiation induction in culture where multinucleated cells were not present (Fig. 2), proliferating muscle satellite cells expressed $\alpha 4$ integrin (Fig. 3). Myotubes were observed from day 15 in the culture and, by the last stage of the culture (day 18), multinucleated myotubes were frequently formed (Fig. 2). In this stage, the muscle satellite cell culture kept $\alpha 4$ integrin expression (Fig. 3), though 
Bovine $\alpha 4$ Integrin cDNA Sequencing

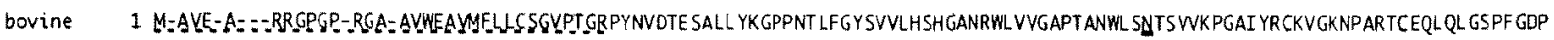
human 1 MFPTESAWLGKRGANPGPEA-AVRET WLLLLCL GVPT GRPYNVDTE SALL YQGPHNTLFGYSWLHSHGANRWLLVG APTANWL ANASVINPGAI YRCR IGKNP GQTCEQLQL GSPNGEP mOUSe 1 MFSTKSAWLRNGGAOQGPRGIALREAWLLL YF GVPT GPSYNLDPENALLYQGPSGTLFYSWLHSHGSKRWLIVGAPTASWLSNASWNPGAIYRCGIRKNPNQTCEQLQSGSPSGEP

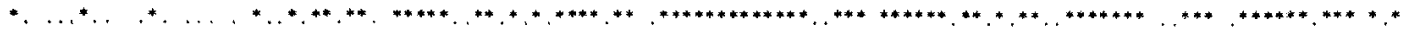

bovine 114 CGKTCLEERDNQWLGVTLSRQPGENGSIVTCGHRWKNIFYIRTESKLPTGVCYOMPSDLRTELSKRIAPCYQDWKQFGENFASCQAGISSFYTEDL IVMGAPGSYYWTOSLFVMMTIN human 120 CGKTCLEERONOWLGVTLSRQPGENGSIVTCGHRWKNIFYIKNENKLPTGGCYGVPPOLRTELSKRIAPCYQDWKKFGENFASCQAGISSFYTKDLIVMGAPGSSYWTGSLFVYNITTN mouse 121 CGKTCLEERONQWLGVTLSRQPGENGSIVTCGHRWKN IF YMKSDNKLPTGICYMPS DL RTELS KRMAPCYKDYTRKFGENFASCQAGISSFYTQDL IVMGAPGSSYWTGTVFVYNITTN

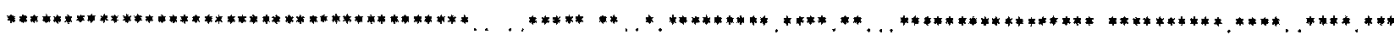

bovine

human

mouse

bovine

human

mouse

bovine

human

mouse

bovine

human

mouse

bovine

human

mouse

bovine

human

mouse

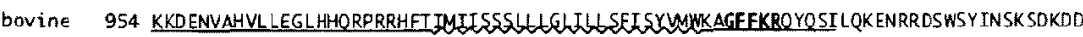

human 960 NKDENVAHVLLEGLHHQQRPKRYFTIVIIS5SLLLGLIVLLLISYWHKAGFFKRQYKSILQEENRRDSWSYINSKSN-DD

mouse 961 NKDENVAHVF LEGLHHQRPKRHFTIIIITISLLLGLIVLLLISCWWKAGFFKRQYKSILOEENRROSWSYWNSKSN-DO

*****
234 KYKAFIDK YNQVKFGSYLGYSVGAGHFR SPRSTEVVGGAPQHEQIGKAYIF SIDAKE LNILHEMKGKKLGSYFGASICAVDLNADGFSDLLVGAPMQST IRE EGRVFVYINSGSGAVMNE

240 KVKAFLOKQNQVKFGSYLGYSVGAGHFR SQHTTEVVGGAPQHEQTGKAYIFSIDEKE LNILHEMKGKKLGSYFGASVCAVDLNADG FSDLLVGAPMQST IREEGRVFVYNSGSGAVMNA 241 QYKAFVDRONQVKFGSYLGYSVGAGHFR SPHTT EVVGGAPQHEQIGKAYIFSTDENE LN IVYEMKGKKLGSYFGASVCAVDL NADGFSDLL VGAPMQST IRE EGRVFVYINSGMGAVMVE

354 METELIGSDKYAARFGESI WNL GDIDNOGFEDVAIGAPQ EDOLQGAIYIYNGR VDGISTTFSQR IEGRQISNSLSMFGQSIS GQIDADNNGYLDVAVGAFRSOSAVLLRTRPVVIVEASL 360 MET NL VGSDKYAARFGESIVNL GDIDNOGFEDVAIGAPQEDDLQGAIY IYNGRADGISSTFSQR IEGLQISKSLSMF GQSISGQIDADNNGYVDVAVGAFRSDSAVLLRTRPVVIVDASL 361 MERVL VGSDKYAARFGESIANL GOIDNOGFEDTATGAPQEDDLRGAVIYNGRVDGISSTYSQR IEGQQISKSLRMF GQSISGQIDAONNGYVDVAVGAFQSDSAVLLRTRPVVIVEASL

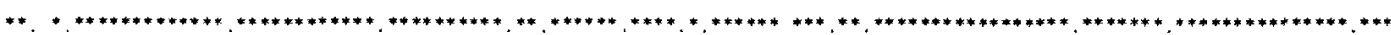

474 NHPESVYR TNFDCIENGLPSVCMDLTLCFSYKGKKVPOYMWLYYMSL DVNRKTESPSR FYFSSNGTYOVITRSIKVQSKATSCKTHQAFMRKDVROILTPIQIEATYHLGHHWSKRSI 480 SHPESVNRTKFDCVENGWPSVCIDLTLCFSYKGKEVPGYIVL FYMSL DVNRKAESPPRFYFSSNGTSOVI TGSIQVSSREANCRTHQAFMRKDVRDIL TPIQIEAAYHLGPHVI SKRST 481 SHPESVNR TKFDCTENGLPSVCMHLTLCFSYKGKEVPGY IVLFYNVSL OVHRKAESP SR FYFFSNGTSOVITGSIRVSS SGEKCRTHQAFMRKDVRD IL TPTHVEATYHLGHHVITKRNT

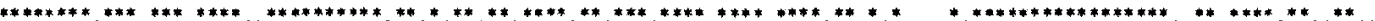

594 EEFPPLQP ILQQKKEKDIIEKT INFARFCAHENCT ADLQVSAKIGF LKPHENKTYLAVGSMKTLMLAVSLYNAGDDAYETTLHIKLPT GL YFIKI LDLEEKQINCEVTDSSGIVRLDCRV 600 EEFPPLQP ILQQKKEKD DMKKT INFARFCAHENCSADLOQVSAKIGF LKPHENKTYLAVGSMKTLMLNVSLFNAGDDAYETTLHVKLPVGLYFIKI LELEEKQINCEVTDNSGVVQLDCSI 601 EEFPPLQPILQQKKEKOVIRKMINFARFCAYENCSADLQVSAKVGF LKPYENKTYLAVGSMKTIMLNVSLFNAGDOAYETTLNVQLPTGLYFIKILDLEEKQINCEVTESSGIVKLACSL

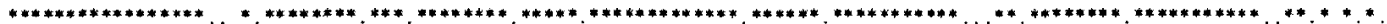

714 GYIYVDHL SKTDVGFLL DASSL SRADEDLNITVHAACENEGETGDVKRNKVTVIIPL KY EVMLT VHGFVSPASFMYGPKEEDEFEMCT TEKMNFTFHVINT GQSMAPNIGVEIMIPNSFS 720 GYIYVOHL SRIDISFLLDVSSL SRAEEDLSITVHATCENEEEMDNL KHSRVTVAIPLKYEVKLT VHGF WNPTSFVYGSN OENEPET OMVEKMNLTFHVINTGNSMAPNVSVEIMNPNSFS 721 GYIYVDRL SRIOISFLLOVSSL SRAHEDLSISVHASCENEGELDQVRDNRVTL TIPLRYEVMLTVHGL WNTSFVYGSEENEPET OMAEKLNLTFHVINTGISMAPNVSVKIMNPNSFL

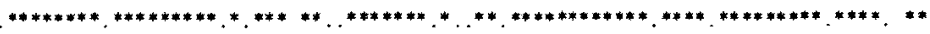

233 whether the expression was spatially restricted to mononucleated cells or not was undefined. Since only slight expression of the $\alpha 4$ integrin was observed in muscle tissue (Fig. 3), this data suggests that the $\alpha 4$ integrin expression of muscle cells is temporally restricted to the early stage of muscle development, but not to the maturation.

\section{Discussion}

The deduced amino acid sequence of the bovine $\alpha 4$ 

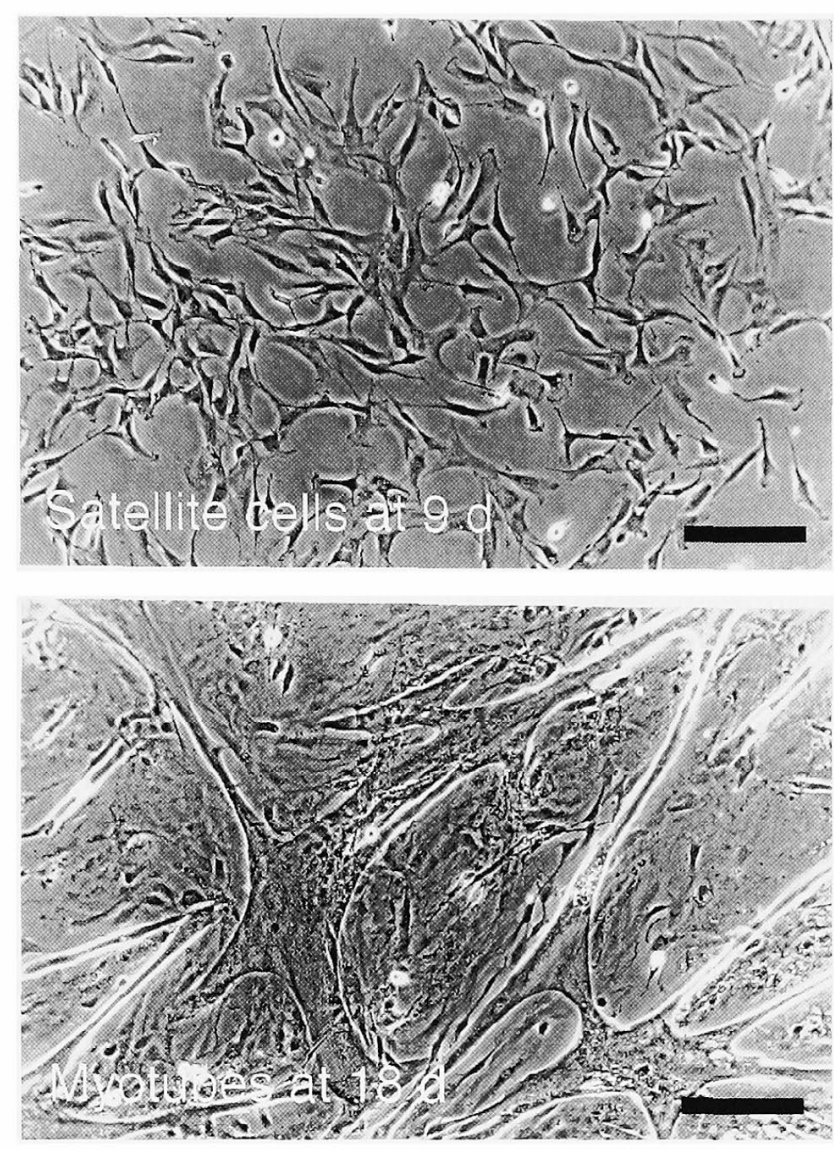

Fig. 2. Primarily-cultured bovine skeletal muscle satellite cells and the myotubes. Myotube formation was enhanced by a serum-free medium at $14 \mathrm{~d}$ in culture (see "Material and Methods"). The bars in photos indicate $200 \mu \mathrm{m}$.

integrin showed that all the functional domains seem to be conserved in its molecular structure. The high similarity between the bovine and the human $\alpha 4$ integrin suggests that all the ligand binding sites in the bovine protein can be adjacent to each other, and are located in the upper face, the predicted ligand binding site, in the $\beta$-propeller model ${ }^{18)}$.

Since a proteolytic cleavage site common in the $\alpha 4$ integrin proteins is conserved in the deduced bovine primary structure, it is expected to be cleaved as are the other species protein. However, the significance of this cleavage is not understood ; it seems likely that the cleavage is not important for ligand binding, as shown by mutation analysis of the site ${ }^{22)}$.

In this study, $\alpha 4$ integrin expression in primarily-

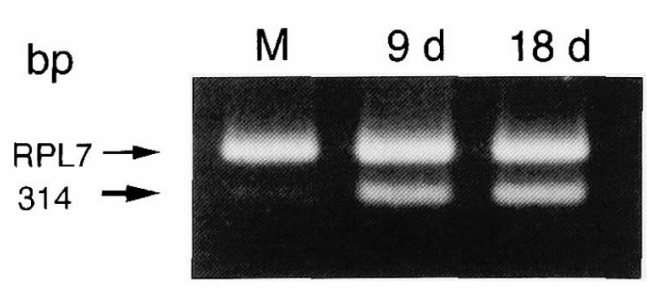

Fig. 3. Expression of $\alpha 4$ integrin in bovine skeletal muscle tissue and the primarily-cultured cells. cDNA templates were synthesized from equivalent total RNAs of skeletal muscle tissue (M) and the cultured satellite cells at each culture point $(9 \mathrm{~d}$ and $18 \mathrm{~d}$ ) and were equivalently applied to the PCR. Size of PCR product is given as bp on the left side. RPL7 : ribosomal protein $\mathrm{L} 7$.

cultured bovine muscle satellite cells was analyzed using bovine $\alpha 4$ integrin specific primers. The slight expression from the skeletal muscle tissue does not contradict the previous immunohistochemical data of adult mice ${ }^{15)}$. Furthermore, $\alpha 4$ integrin expression in proliferating muscle cells could be detected, as well as in the differentiated cells. On the other hand, Rosen et al. ${ }^{15)}$ could detect the $\alpha 4$ integrin expression only during myotube formation, especially on the myotubes, by northern blot and immunocytochemical analyses. This discrepancy could be due to the difference in the cell types between the primary culture and cell line, or the differences between species, but the primary reason for the discrepancies has not been defined.

Despite the previous data of the mouse cell line, our present result is supported by synchronous expression of VCAM-1 before myogenic differentiation in the bovine mononucleated cells ${ }^{10)}$. Therefore, some ligand interaction of the $\alpha 4$ integrin may occur before myotube formation of muscle satellite cells. Recently, the role of $\alpha 4$ integrin as a signaling mediator has been reported : $\alpha 4 \beta 1$ integrin can downregulate the metalloproteinases in fibroblasts via the adhesion to the CS-1 region of fibronectin ${ }^{4)}$, and protein kinase C-induced cell spreading appeared to be due to activation of $\alpha 4$ integrin in muscle cells ${ }^{3)}$. Such roles to regulate gene expression and to modulate cell morphology could be expected of the $\alpha 4$ integrin on the mononucleated cells via the interaction before 
Bovine $\alpha 4$ Integrin cDNA Sequencing

myotube formation.

\section{Acknowledgments}

This study was supported in part by a Grant-in-aid (Bio Design Program) from the Ministry of Agriculture, Forestry, and Fisheries, Japan (BDP-01-III-2-2).

\section{References}

1) Bittner M, Gossler U, Luz A, Holzmann B. Sequence motifs in the integrin $\alpha 4$ cytoplasmic tail required for regulation of in vivo expansion of murine lymphoma cells. Journal of Immunology, 161 : 5978-5986. 1998.

2) Dean DC, Iademarco MF, Rosen GD, Sheppard AM. The integrin $\alpha 4 \beta 1$ and its counter-receptor VCAM-1 in development and immune function. American Review of Respiratory Diseases, $148:$ : 43 s46. 1993.

3) Disatnik MH, Rando TA. Integrin-mediated muscle cell spreading. The role of protein kinase $\mathrm{C}$ in outside-in and inside-out signaling and evidence of integrin cross-talk. Journal of Biological Chemistry, 274 : 32486-32492. 1999.

4) Huhtala $\mathbf{P}$, Humphries MJ, McCarthy JB, Tremble PM, Werb Z, Damsky CH. Cooperative signaling by $\alpha 5 \beta 1$ and $\alpha 4 \beta 1$ integrins regulates metalloproteinase gene expression in fibroblasts adhering to fibronectin. Journal of Cell Biology, $129: 867-879.1995$.

5) Irie A, Kamata T, Puzon-McLaughlin W, Takada $Y$. Critical amino acid residues for ligand binding are clustered in a predicted $\beta$-turn of the third $\mathrm{N}$ terminal repeat in the integrin $\alpha 4$ and $\alpha 5$ subunits. EMBO Journal, 14 : 5550-5556. 1995.

6) Irie A, Kamata T, Takada Y. Multiple loop structures critical for ligand binding of the integrin $\alpha 4$ subunit in the upper face of the $\beta$-propeller model. Proceedings of National Academy of Sciences of the United States of America, 94 : 7198-7203. 1997.

7) Ivasca J, Heino J. Adhesion receptors and cell invasion : mechanisms of integrin-guided degradation of extracellular matrix. Cellular and Molecular Life Sciences, 57 : 16-24. 2000.

8) Jesse TL, LaChance R, Iademarco MF, Dean DC. Interferon regulatory factor- 2 is a transcriptional activator in muscle where it regulates expression of vascular cell adhesion molecule-1. Journal of Cell Biology, 140 : 1265-1276. 1998.

9) Masumoto A, Hemler ME. Mutation of putative divalent cation sites in the alpha 4 subunit of the integrin VLA-4 : distinct effects on adhesion to CS1/ fibronectin, VCAM-1, and invasin. Journal of Cell Biology, 123 : 245-253. 1993.

10) Muroya S, Nakajima I, Chikuni K. Bovine skeletal muscle satellite cells predominantly express a vascular cell adhesion molecule-1 seven-Ig domain splice form. Zoological Science, 2001. (in press.)

11) Nara H, Imanaka T, Yamaguchi T. Enhanced expression of acetylcholineesterase activity in bovine satellite cells treated with insulin-like growth factor I. Animal Science Journal, 71:63-70. 2000.

12) Neuhaus $\mathrm{H}, \mathrm{Hu} \mathrm{MCT}$, Hemler ME, Takada $\mathrm{Y}$, Holzmann B, Weissman IL. Cloning and expression of cDNAs for the a subunit of the murine lymphocyte-Peyer's patch adhesion molecule. Journal of Cell Biology, 115: 1149-1158. 1991.

13) Ontel M, Hughes D, Bourke D. Morphometric analysis of the developing mouse soleus muscle. American Journal of Anatomy, $181: 279-288.1988$.

14) Rojiani MV, Finlay BB, Gray V, Dedhar S. In vitro interaction of a polypeptide homologous to human Ro/SS-A antigen (calreticulin) with a highly conserved amino acid sequence in the cytoplasmic domain of integrin $\alpha$ subunits, Biochemistry, 30: 9859-9866. 1991.

15) Rosen GD, Sanes JR, LaChance R, Cunningham JM, Roman J, Dean DC. Roles for the integrin VLA4 and its counter receptor VCAM-1 in myogenesis. Cell, 69 : 1107-1119. 1992.

16) Ross JJ, Duxson MJ, Harris AJ. Formation of primary and secondary myotubes in rat lumbrical muscles. Development, $100: 383-394.1987$.

17) Sheppard AM, Onken MD, Rosen GD, Noakes PG Dean DC. Expanding roles for $\alpha 4$ integrin and its ligands in development. Cell Adhesion and Communication, $2: 27-43.1994$.

18) Springer TA. Folding of the $\mathrm{N}$-terminal, ligandbinding region of integrin $\alpha$-subunits into a $\beta$ propeller domain. Proceedings of National Academy of Sciences of the United States of America, $94: 65-$ 72. 1997.

19) Stepp MA, Urry LA, Hynes RO. Expression of $\alpha 4$ integrin mRNA and protein fibronectin in the early chicken embryo. Cell Adhesion and Communication, $2: 359-375.1994$.

20) Stockdale FEF, Miller JB. The cellular basis of myosin heavy chain isoform expression during development of avian skeletal muscles. Developmental Biology, $123: 1$-9. 1987.

21) Takada $Y$, Elices MJ, Crouse $C$, Hemler ME. The primary structure of the $\alpha 4$ subunit of VLA-4: 


\section{MUROYA, NAKAJIMA and CHIKUNI}

Homology to the other integrins and a possible cellcell adhesion function. EMBO Journal, 8: 13611368. 1989.

22) Pujades C, Teixido J, Bazzoni G, Hemler ME. Integrin $\alpha 4$ cysteines 278 and 717 modulate VLA-4 ligand binding and also contribute to $\alpha 4 / 180$ formation. Biochemical Journal, 313: 899-908. 1996.

23) Whittakker CA, Desimone DW. Molecular cloning and developmental expression of the Xenopus homo$\log$ of integrin $\alpha 4$. Annals of the New York Academy of Sciences, 857 : 56-73. 1998.

24) Yang JT, Rayburn H, Hynes RO. Cell adhesion events mediated by $\alpha 4$ integrins are essential in placental and cardiac development. Development, 121 : 549-560. 1995. 